\title{
Agrobacterium tumefaciens-mediated transformation of Aspergillus aculeatus for insertional mutagenesis
}

\author{
Emi Kunitake, Shuji Tani, Jun-ichi Sumitani and Takashi Kawaguchi
}

\begin{abstract}
Agrobacterium tumefaciens-mediated transformation (AMT) was applied to Aspergillus aculeatus. Transformants carrying the T-DNA from a binary vector $\mathrm{pBIG} 2 \mathrm{RHPH} 2$ were sufficiently mitotically stable to allow functional genomic analyses. The AMT technique was optimized by altering the concentration of acetosyringone, the ratio and concentration of A. tumefaciens and A. aculeatus cells, the duration of co-cultivation, and the status of $A$. aculeatus cells when using conidia, protoplasts, or germlings. On average, 30 transformants per $10^{4}$ conidia or 217 transformants per $10^{7}$ conidia were obtained under the optimized conditions when A. tumefaciens co-cultured with fungi using solid or liquid induction media (IM). Although the transformation frequency in liquid IM was 100-fold lower than that on solid IM, the AMT method using liquid IM is better suited for high-throughput insertional mutagenesis because the transformants can be isolated on fewer selection media plates by concentrating the transformed germlings. The production of two albino A. aculeatus mutants by AMT confirmed that the inserted TDNA disrupted the polyketide synthase gene Aapks $P$, which is involved in pigment production. Considering the efficiency of AMT and the correlation between the phenotypes and genotypes of the transformants, the established AMT technique offers a highly efficient means for characterizing the gene function in A. aculeatus.
\end{abstract}

Keywords: TAlL-PCR, gene tagging, insertional mutagenesis

\section{Introduction}

The imperfect fungus Aspergillus aculeatus no. F-50 [NBRC 108796], which was isolated from soil in our laboratory, forms black-pigmented asexual spores similar to those of Aspergillus niger. This A. aculeatus strain produces cellulases and hemicellulases that are applicable for synergistic pulp hydrolysis in combination with cellulases from Trichoderma reesei (Murao et al. 1979). Another feature of $A$. aculeatus is its ability to secrete endogenous proteins in high quantities; $A$. aculeatus expresses its own $\beta$-mannosidase at levels 9 times greater than those of $A$. oryzae, which is one of the most widely used hosts for protein production (Kanamasa et al. 2007). Therefore, we aimed to genetically modify $A$. aculeatus to create a high-quality host for the production of autologous cellulases and hemicellulases, and thereby facilitate the production of effective

\footnotetext{
* Correspondence: shuji@biochem.osakafu-u.ac.jp

Graduate School of Life and Environmental Sciences, Osaka Prefecture University, 1-1 Gakuen-cho, Naka-ku, Sakai, Osaka 599-8531, Japan
}

enzymes for the saccharification of unutilized cellulosic biomass and its subsequent bioconversion. To achieve this goal, a method to increase the amount of secreted enzymes is necessary. Although it is important to understand the molecular mechanisms underlying the effective secretion of endogenous enzymes and the associated gene regulation mechanisms, these mechanisms remain unclear (Ooi et al. 1999,; Takada et al. 1998, and 2002). Thus, there is an increasing need to establish methods for functional genetic analyses in A. aculeatus.

Random insertional mutagenesis is an efficient forward genetic technique for identifying the cellular roles of genes. One valuable method entails transferring a known gene into the recipient genome at random, as analyses of the phenotypes resulting from gene inactivation or modification can provide insight into the function of the affected genes. Transposon-mediated directed mutations and restriction-enzyme-mediated integrations (REMI) have long been applied for random insertional mutagenesis in fungal species (Braumann et 
al. 2007,; Brown et al. 1998,; Daboussi 1996,; Linnemannstöns et al. 1999). However, both methods tend to multiply the transposable elements or transfer multiple copies of inserted plasmids into the recipient genome. These phenomena are disadvantageous when performing insertional mutagenesis in filamentous fungi such as $A$. aculeatus, for which a feasible genetic segregation analysis is unavailable. Recently, there has been a trend toward adopting Agrobacterium tumefaciens-mediated transformation (AMT) for insertional mutagenesis; this method has been widely used as a genetic engineering technique for plant cells (Feldmann 1991,; Koncz et al. 1992) and more recently adapted to fungi including Magnaporthe oryzae (Betts et al. 2007,; Meng et al. 2007), Fusarium oxysporum (Mullins et al. 2001), Colletotrichum lagenarium (Tsuji et al. 2003), Cryptococcus neoformans (Idnurm et al. 2004), Aspergillus fumigatus (Sugui et al. 2005), and Aspergillus awamori (de Groot et al. 1998). This transformation technique utilizes the ability of A. tumefaciens to transfer DNA (so-called TDNA, which is located between two direct repeats, i.e., the left and right borders) to its host cells in the presence of a phenolic compound such as acetosyringone. The T-DNA is transferred as a single-stranded DNA into recipient cells by the Type IV secretion system (Backert and Meyer 2006,; Christie 2001,) and predominantly integrated as a single copy into the transformant genome (Betts et al. 2007,; Michielse et al. 2005b,; Tsuji et al. 2003).

Although it has been previously demonstrated that $A$. tumefaciens is capable of transforming various fungi including the Ascomycetes, the transformation conditions must be optimized because the transformation frequencies vary among fungal species and strains. To establish an efficient AMT method for high-throughput insertional mutagenesis in A. aculeatus, we optimized the AMT conditions to effectively isolate transformants harboring single-copy T-DNA insertions at random loci. We also demonstrated that the established AMT method is applicable for functional genetic analyses.

\section{Materials and methods}

\section{Strains and plasmids}

A. tumefaciens $\mathrm{C} 58 \mathrm{C} 1$ and the binary vector pBIG2RHPH2, which carries a hygromycin B-resistant gene between the left and right T-DNA borders, were kindly provided by Dr. Tsuji (Tsuji et al. 2003). A. aculeatus strains were propagated at $30^{\circ} \mathrm{C}$ in minimal media (MM) supplemented appropriately, unless stated otherwise (Adachi et al. 2009). Conidia of transformants were purified by repeating mono-spore isolation twice on MM plates to obtain the conidia of homokaryons.

\section{Cloning and expression of Aapks $P$}

The polyketide synthase gene AapksP along with the regions 1,041-bp upstream and 567-bp downstream of the open reading frame was amplified by PCR with PrimeSTAR HS DNA polymerase (TaKaRa, Japan) and the primers pks-F_Nhe and pks-R_Nhe (Table 1) using $A$. aculeatus genomic DNA as a template. PCR condition is as described in manufacture's instruction except for setting annealing temperatures and PCR cycles as $65^{\circ} \mathrm{C}$ and 30 cycles. The amplified DNA fragments were sequenced, digested with Nhe I, and ligated into pAUR325 (TaKaRa, Japan) to yield pAUR-PksP. The transformation of $A$. aculeatus was performed by the protoplast method (Adachi et al. 2009) using the circular plasmids pAUR325 and pAUR-PksP. Transformants were selected on $3.5 \mu \mathrm{g} / \mathrm{ml}$ Aureobasidin A.

\section{Agrobacterium tumefaciens-mediated transformation (AMT)}

AMT was performed as described in Tsuji et al. (2003) with minor modifications. A. tumefaciens C58C1 harboring pBIG2RHPH2 was grown in liquid LB medium supplemented with $30 \mu \mathrm{g} / \mathrm{ml}$ of kanamycin and $100 \mu \mathrm{g} / \mathrm{ml}$ of rifampicin at $28^{\circ} \mathrm{C}$ for 18 hours. The culture was diluted to an optical density at $660 \mathrm{~nm}\left(\mathrm{OD}_{660}\right)$ of 0.15 in $100 \mathrm{ml}$ of induction medium (IM) with $200 \mu \mathrm{M}$ acetosyringone (AS), $30 \mu \mathrm{g} / \mathrm{ml}$ of kanamycin, and $100 \mu \mathrm{g} / \mathrm{ml}$ rifampicin. The cells were grown at $24^{\circ} \mathrm{C}$ until the $\mathrm{OD}_{660}$ reached $0.2-0.8$. The average numbers of $A$. tumefaciens cells in $100 \mu \mathrm{l}$ of culture medium at $\mathrm{OD}_{660}$ $=0.2,0.4,0.6,0.8$, and 1.0 were calculated as $2.5 \times 10^{7}$, $5 \times 10^{7}, 7.5 \times 10^{7}, 1 \times 10^{8}$, and $1.25 \times 10^{8}$ cells, respectively, using a colony-counting method. In the co-cultivation on solid IM, a mixture of $100 \mu \mathrm{l}$ of $A$. tumefaciens suspension and $10^{4} \mathrm{~A}$. aculeatus conidia was spread onto filter paper (hardened, low-ash grade 50; Whatman, Maidstone, UK) on IM containing 200 $\mu \mathrm{M}$ acetosyringone (AS). After co-cultivation for 24-72 $\mathrm{h}$ at $24^{\circ} \mathrm{C}$, the filter paper was transferred to the selection medium (SM; MM containing $100 \mu \mathrm{g} / \mathrm{ml}$ of hygromycin $\mathrm{B}$ and $100 \mu \mathrm{g} / \mathrm{ml}$ of cefotaxime). When cocultivation was performed in liquid IM, A. tumefaciens was cultured to $\mathrm{OD}_{660}=0.4$, harvested by centrifugation, and co-cultivated with $10^{7}$ of $A$. aculeatus conidia in liquid IM containing $200 \mu \mathrm{M}$ AS. After shaking at $120 \mathrm{rpm}$ for $16-96$ hours at $24^{\circ} \mathrm{C}$, the germlings were harvested and incubated on SM.

\section{Molecular analyses of transformants}

Conidia from the transformants were grown in $\mathrm{MM}$ containing $100 \mu \mathrm{g} / \mathrm{ml}$ of hygromycin $\mathrm{B}$ at $30^{\circ} \mathrm{C}$ for 50 hours on a shaker (170 rpm). Genomic DNA was 
Table 1 Primers used in this study

\begin{tabular}{lll}
\hline Name & Sequence (5' to 3') $^{\prime}$ & \\
\hline HS-1com1 & TGCTCCATACAAGCCAACC & \\
HAS-2com & ATCATCTGCTGCTTGGTGC & \\
AD-2 & NGTCGASWGANAWGAA & \\
AD-3 & GTNCGASWCANAWGT & \\
HS-1 & WGTGNAGWANCANAGA & 436 bp from nick site in RB ${ }^{\text {a }}$ \\
HS-2 & GGCCGTGGTTGGTTGTATGGAGCAGCAGA & 336 bp from nick site in RB \\
HS-3 & TGGTCTTGACCAACTCTATCAGAGCTT & 193 bp from nick site in RB \\
HS-4 & GGACCGATGGCTGTGTAGAAGTA & 170 bp from nick site in RB, for sequencing \\
HAS-2 & CTCGCCGATAGTGGAAACC & 373 bp from nick site in LB \\
HAS-3 & GCACCAAGCAGCAGATGAT & 354 bp from nick site in LB \\
HAS-4 & AATAATGTCCTCGTTCCTGTCTGCTAATAA & 225 bp from nick site in LB \\
HAS-5 & CCGCCTGGACGACTAAAC & 187 bp from nick site in LB, for sequencing \\
pks-F_Nhe & GACCTCCACTAGCTCCAGCC & \\
pks-R_Nhe & taggctagcGTAAGCTCACCGTCAAGGCA & \\
\hline
\end{tabular}

${ }^{\mathrm{a}} \mathrm{RB}$, right border; ${ }^{\mathrm{b}} \mathrm{LB}$, left border

isolated as described in Adachi et al. (2009) from mycelia and was digested with EcoR I and Sal I or Xba I and $H i n d$ III. The EcoR I and $X b a$ I recognition sites are located within the T-DNA region at positions 124 and $81 \mathrm{nt}$ from the left and right border nick sites, respectively. The digestion of genomic DNA with EcoR I or $X b a$ I in combination with Sal I or Hind III, for which there are no recognition sites on pBIG2RHPH2, yields relatively shorter fragments and thus helps to distinguish the fragment size. Hybridization was performed as described in Adachi et al. (2009) using an 880-bp fragment amplified with $h p h$-specific primers (HS-1com1 and HAS-2com) as a DNA probe (Table 1).

A thermal asymmetric interlaced polymerase chain reaction (TAIL-PCR) was performed to obtain DNA sequences flanking the T-DNA insertions in the fungal transformants, following the methods described in Liu et al. (1995), and Sessions et al. (2002) with minor modifications, as summarized in Table 2. The T-DNA specific (left border, HAS-2-4; right border, HS-1-3) and arbitrary degenerate primers (AD1-3) are described in Table 1. The final concentrations of the T-DNA-specific primers were adjusted to $0.4 \mu \mathrm{M}$ and those of the AD primers were 3-4 $\mu \mathrm{M}$ (depending on the degree of degeneracy) in the primary reaction and $2 \mu \mathrm{M}$ in the secondary and tertiary reactions. The amplified tertiary PCR products were subjected to agarose gel electrophoresis and sequence analysis. TAIL-PCR was also performed with a recipient genome digested with $B g l$ II, EcoR I or Xba I. Bgl II sites are located outside the TDNA region at positions 511 and 133 nt from the left and right border nick sites, respectively. Thus, digestion with these restriction enzymes produces T-DNA fragments carrying either side of the flanking sequence tag even when the T-DNA, with or without the vector backbone, is integrated into a recipient genome as concatemeric bands.

Inverse PCR was also applied to rescue the flanking sequences. Genomic DNA from each transformant was digested with Nco I, Nde I (both located in the middle of the T-DNA), EcoR I, or both Xba I and Spe I and used as a template for inverse PCR. Spe I was used to increase the possibility of obtaining fragments flanking

\section{Table 2 Thermal settings for TAIL-PCR}

\begin{tabular}{|c|c|}
\hline Reaction and cycle & Thermal settings \\
\hline \multicolumn{2}{|l|}{ Primary } \\
\hline 1 & $93^{\circ} \mathrm{C}, 1$ min.; $95^{\circ} \mathrm{C}, 1 \mathrm{~min}$ \\
\hline 5 & $\begin{array}{l}98^{\circ} \mathrm{C}, 30 \mathrm{sec} . ; 62^{\circ} \mathrm{C}, 15 \mathrm{sec} . ; 72^{\circ} \mathrm{C}, 3 \mathrm{~min} . \\
98^{\circ} \mathrm{C}, 30 \mathrm{sec} . ; 25^{\circ} \mathrm{C}, 3 \mathrm{~min} . ;\end{array}$ \\
\hline 1 & $\begin{array}{l}\text { ramping to } 72^{\circ} \mathrm{C} \text {, over } 3 \text { min.; } 72^{\circ} \mathrm{C}, 3 \mathrm{~min} \text {. } \\
98^{\circ} \mathrm{C} \text {, } 10 \text { sec.; } 68^{\circ} \mathrm{C} \text {, } 15 \mathrm{sec} \text {; } 72^{\circ} \mathrm{C}, 3 \mathrm{~min} \text {.; }\end{array}$ \\
\hline 15 & $\begin{array}{l}98^{\circ} \mathrm{C}, 10 \mathrm{sec} \text {; } 68^{\circ} \mathrm{C}, 15 \mathrm{sec} . ; 72^{\circ} \mathrm{C}, 3 \mathrm{~min} . ; \\
98^{\circ} \mathrm{C}, 10 \mathrm{sec} . ; 44^{\circ} \mathrm{C}, 15 \mathrm{sec} \text {; } 72^{\circ} \mathrm{C}, 3 \mathrm{~min} .\end{array}$ \\
\hline 1 & $72^{\circ} \mathrm{C}, 5 \mathrm{~min}$ \\
\hline \multicolumn{2}{|l|}{ Secondary } \\
\hline 1 & $\begin{array}{l}93^{\circ} \mathrm{C}, 2 \mathrm{~min} . \\
98^{\circ} \mathrm{C}, 10 \mathrm{sec} . ; 64^{\circ} \mathrm{C}, 15 \mathrm{sec} . ; 72^{\circ} \mathrm{C}, 3 \mathrm{~min} . ;\end{array}$ \\
\hline 12 & $\begin{array}{l}98^{\circ} \mathrm{C}, 10 \mathrm{sec} . ; 64^{\circ} \mathrm{C}, 15 \mathrm{sec} . ; 72^{\circ} \mathrm{C}, 3 \mathrm{~min} \text {; } \\
98^{\circ} \mathrm{C}, 10 \mathrm{sec} . ; 44^{\circ} \mathrm{C}, 15 \mathrm{sec} . ; 72^{\circ} \mathrm{C}, 3 \mathrm{~min} .\end{array}$ \\
\hline 1 & $72^{\circ} \mathrm{C}, 5 \mathrm{~min}$ \\
\hline \multicolumn{2}{|l|}{ Tertiary } \\
\hline 1 & $\begin{array}{l}93^{\circ} \mathrm{C}, 2 \mathrm{~min} . \\
98^{\circ} \mathrm{C}, 10 \mathrm{sec} . ; 68^{\circ} \mathrm{C}, 15 \mathrm{sec} . ; 72^{\circ} \mathrm{C}, 3 \mathrm{~min} . ;\end{array}$ \\
\hline 12 & $\begin{array}{l}98^{\circ} \mathrm{C}, 10 \mathrm{sec} . ; 68^{\circ} \mathrm{C}, 15 \mathrm{sec} . ; 72^{\circ} \mathrm{C}, 3 \mathrm{~min} \text {.; } \\
98^{\circ} \mathrm{C}, 10 \mathrm{sec} . ; 44^{\circ} \mathrm{C}, 15 \mathrm{sec} . ; 72^{\circ} \mathrm{C}, 3 \mathrm{~min} .\end{array}$ \\
\hline 1 & $72^{\circ} \mathrm{C}, 5 \mathrm{~min}$ \\
\hline
\end{tabular}


the T-DNA because there are no Spe I recognition sites inside of the T-DNA, and this enzyme yields cohesive ends that are complementary with those produced by $\mathrm{Xba}$ I. Using genomic DNA digested with Nco I or Nde I as templates, the flanking sequences adjacent to the left and right borders were amplified with the primer sets HAS-4 and HAS-2com or HS-3 and HS-1com1, respectively. When genomic DNA digested with EcoR I or Xba I/Spe I was used as the template, the flanks of both sides of the borders were amplified with the primer sets HAS- 4 and HS-3, respectively. The amplified DNA fragments were sequenced with the primer sets HS-4 and HAS-5.

\section{Mitotic stability}

Nine randomly selected transformants were cultured on $\mathrm{MM}$ in the absence of hygromycin B for 5 generations. Approximately 100 conidia derived from each 5 th generation were spread on MM with or without $100 \mu \mathrm{g} / \mathrm{ml}$ of hygromycin B.

\section{Results}

A. tumefaciens-mediated transformation (AMT) of $A$. aculeatus no. F-50 on solid IM

To determine whether or not AMT is applicable for $A$. aculeatus transformation, we first co-cultivated $1 \times 10^{4}$, $10^{5}$, or $10^{6}$ wild-type A. aculeatus conidia and an $A$. tumefaciens culture at $\mathrm{OD}_{660}=0.8$ on induction media (IM) supplemented with $200 \mu \mathrm{M}$ of acetosyringone (AS) at $24^{\circ} \mathrm{C}$ for 48 hours, as described in the protocol for the AMT of Colletotrichum (Tsuji et al. 2003). Because the transformants were produced using, at most, $1 \times$ $10^{4}$ of A. aculeatus conidia (data not shown), we further assessed the AMT conditions on IM plates with regard to the ratio of $A$. tumefaciens and A. aculeatus cells, the duration of co-cultivation, and the $A$. aculeatus starting material. Various concentrations of $A$. tumefaciens cells, at $\mathrm{OD}_{660}=0.2-0.8$, were co-cultivated with $1 \times 10^{4}$ of A. aculeatus conidia at $24^{\circ} \mathrm{C}$ for 24,48 , and 72 hours. The results in Table 3 demonstrate that the transformation frequency increased in relation to the co-cultivation time and bacterial dosage, although prolonged co-cultivation periods (at 72 hours) and co-cultivation using a high concentration of $A$. tumefaciens $\left(\mathrm{OD}_{660}=1.0\right)$ tended to yield transformants with severe growth defects such as impaired hyphal elongation and conidiation. We consequently obtained a maximum transformation frequency of 30 transformants per $1 \times 10^{4}$ conidia, on average, when $1 \times 10^{4}$ conidia of $A$. aculeatus were mixed with $1 \times 10^{8}$ bacterial cells $\left(\mathrm{OD}_{660}=0.8\right)$ and cocultivated for 48 hours on IM plates. Protoplasts and conidia were transformed with equal efficiency by $A$. tumefaciens (data not shown), which enabled us to omit the intricate handling for protoplast preparation. The relatively large standard deviation in these and later experiments presumably reflects the general nature of the transformation in Aspergillus.

One rationale for optimizing AMT conditions for $A$. aculeatus was to allow insertional mutagenesis by $\mathrm{T}$ DNA insertion. To help reduce the labor requirement of the numerous media preparations or transfer of many transformants from IM to SM plates, we investigated ways in which more transformants could be obtained on an SM plate by increasing the total amount of mixed $A$. tumefaciens $\left(\mathrm{OD}_{660}=0.8\right)$ and conidia spread onto an IM plate while holding the ratio of conidia to A. tumefaciens cells at the optimum value $\left(1: 10^{4}\right)$. Unexpectedly, increasing the amount of this mixture did not increase the number of transformants per plate in a dose-dependent manner because the transformation frequency was reduced (Table 4). This result suggests that critical parameters for efficient AMT include not only the ratio between bacterial cells and recipient cells, but also the density of their mixture during the infection.

\section{Optimization of AMT conditions of $A$. aculeatus in liquid IM}

We presumed that the failure to increase the transformant yield by increasing the total number of conidia and bacterial cells per plate was the result of the inefficient infection of the fungus by $A$. tumefaciens on IM plates. Therefore, we expected that transformants could

Table 3 Optimization of ratios of fungal conidia to bacterial cells and co-cultivation periods on IM plates

\begin{tabular}{|c|c|c|c|c|c|}
\hline \multirow[t]{2}{*}{$\begin{array}{l}\text { Number of } \\
\text { conidia }\end{array}$} & \multirow{2}{*}{$\begin{array}{l}\mathrm{OD}_{660} \text { of } \\
\text { Agrobacterium } \\
\text { culture }\end{array}$} & \multirow[t]{2}{*}{$\begin{array}{l}\text { Ratio of conidia: } \\
\text { Agrobacterium }\end{array}$} & \multicolumn{3}{|c|}{$\begin{array}{l}\text { Mean of transformants } \pm S D / 10^{4} \\
\text { conidia }\end{array}$} \\
\hline & & & $24 \mathrm{~h}$ & $48 h$ & $72 \mathrm{~h}$ \\
\hline $1 \times 10^{4}$ & 0.2 & $1: 2.5 \times 10^{3}$ & n.d. ${ }^{b}$ & $8 \pm 7(n=4)$ & n.d. \\
\hline $1 \times 10^{4}$ & 0.4 & $1: 5 \times 10^{3}$ & n.d. & $7 \pm 6(n=6)$ & n.d. \\
\hline $1 \times 10^{4}$ & 0.6 & $1: 7.5 \times 10^{3}$ & n.d. & $10 \pm 7(n=4)$ & n.d. \\
\hline $1 \times 10^{4}$ & 0.8 & $1: 10^{4}$ & $1 \pm 1\left(n^{a}=2\right)$ & $30 \pm 28(n=12)$ & $34 \pm 27(n=2)$ \\
\hline $1 \times 10^{4}$ & 1.0 & $1: 1.25 \times 10^{3}$ & n.d. & $62 \pm 20(n=2)$ & n.d. \\
\hline
\end{tabular}

${ }^{a} n$, number of independent experiments.

${ }^{b}$ n.d., not done. 
Table 4 The effect of concentration of the fungal and bacterial cells on AMT

\begin{tabular}{|c|c|c|c|c|}
\hline $\begin{array}{l}\text { Number } \\
\text { of } \\
\text { conidia }\end{array}$ & $\begin{array}{l}\text { Amount of } \\
\text { Agrobacteria } \\
\text { culture }(\mathrm{ml})\end{array}$ & $\begin{array}{l}\text { Ratio of } \\
\text { conidia: } \\
\text { Agrobacterium }\end{array}$ & $\begin{array}{l}\text { Mean of } \\
\text { transformants } \\
\pm \text { SD/plate }\end{array}$ & $\begin{array}{l}\text { Number of } \\
\text { transformants } \\
/ 10^{4} \text { conidia }\end{array}$ \\
\hline $1 \times 10^{4}$ & 0.1 & $1: 10^{4}$ & $\begin{array}{l}30 \pm 28\left(n^{a}=\right. \\
12)\end{array}$ & $30 \pm 28$ \\
\hline $2 \times 10^{4}$ & 0.2 & $1: 10^{4}$ & $\begin{array}{l}52 \pm 10(n= \\
2)\end{array}$ & $26 \pm 5$ \\
\hline $5 \times 10^{4}$ & 0.5 & $1: 10^{4}$ & $\begin{array}{l}51 \pm 13(n= \\
2)\end{array}$ & $10 \pm 2$ \\
\hline $1 \times 10^{5}$ & 1 & $1: 10^{4}$ & $\begin{array}{l}39 \pm 14(n= \\
6)\end{array}$ & $3 \pm 1$ \\
\hline $1 \times 10^{6}$ & 10 & $1: 10^{4}$ & $16 \pm 9(n=3)$ & $<1$ \\
\hline
\end{tabular}

${ }^{a} n$, number of independent experiments.

be obtained from a high density of infected germlings on SM plates after A. tumefaciens cells had successfully infected the fungus at the best ratio and concentration, followed by filtration to concentrate the infected germlings and subsequent transfer to SM plates. Furthermore, it has been reported that the co-cultivation of B. lamprospora in liquid IM facilitates the transmission of the foreign DNA when compared with cultivation on the surface of solid IM (Nyilasi et al. 2008). We next optimized the AMT conditions using liquid IM. As shown in Table 5, we obtained 217 transformants, on average, when $1 \times 10^{7}$ conidia of $A$. aculeatus were mixed with 5 $\times 10^{8}$ bacterial cells and co-cultivated in $100 \mathrm{ml}$ of liquid IM including $200 \mu \mathrm{M}$ of AS for 48 hours with shaking at $120 \mathrm{rpm}$. Among the concentrations of AS investigated $(0,50,100,200$, and $400 \mu \mathrm{M}), 200 \mu \mathrm{M}$ was selected for subsequent trials because this concentration yielded the most transformants. Co-cultivation for 60 hours yielded more transformants than at 48 hours; however, more transformants with growth defects tended to emerge on the SM plates. We again investigated the effects of a higher concentration of A. tumefaciens cells and conidia in liquid IM with the same ratio of $A$. tumefaciens cells to conidia (50:1), but the number of transformants did not increase in a dose-dependent manner. This result may have been caused by an insufficient supply of AS for the A. tumefaciens cells to express the virulence genes because the concentration of
AS was held at $200 \mu \mathrm{M}$. However, keeping the effective concentration of AS at the optimal level in relation to the amount of A. tumefaciens cells did not increase the number of transformants obtained (data not shown). Although the transformation frequency in liquid IM showed a 100-fold reduction compared with the solid IM, this transformation method is suitable for random insertional mutagenesis because fewer SM plates are required for the transfer of transformants from IM to SM plates. Therefore, we propose that performing AMT using liquid IM is a practical means for high-throughput insertional mutagenesis.

\section{Optimizing AMT conditions for different isolates}

The transformation frequency tends to vary among different isolates of the same fungal species when AMT is performed using a method optimized for the standard strain (Roberts et al. 2003,; Sullivan et al. 2002,). The transformation frequency is also affected by slight differences in transformation conditions or the physiological state of the recipient cells (Michielse et al. 2005a). To investigate the AMT frequencies of different $A$. aculeatus isolates, we first compared the AMT frequencies of the $A$. aculeatus wild-type and a uridine auxotroph, the pyrG mutant. Because uridine must be added to liquid IM and SM plates to grow the pyrG mutant, we first assessed the effect of uridine addition on the AMT of the $A$. aculeatus wild-type (Table 6). In the wild-type, although the addition of $0.2 \%$ uridine to the liquid IM did not affect the number of transformants per $10^{7}$ conidia per $100 \mathrm{ml} \mathrm{IM}$, the addition of $0.01 \%$ uridine, which was the minimum concentration for the growth of the A. aculeatus pyrG mutant on MM plates, reduced the number of transformants by half in all trials except for the $24 \mathrm{~h}$ co-cultivation period (Table 6). Using conidia from the pyrG mutant as a starting material, the maximum number of transformants $(135 \pm 155)$ per $10^{7}$ conidia per $100 \mathrm{ml} \mathrm{IM}$ was obtained at $60 \mathrm{~h}$ of cocultivation with $0.2 \%$ uridine. The reduction of the transformation frequency and the long duration of the co-cultivation compared with the wild-type may be related to the reduced germination rate of the recipient conidia because the $\operatorname{pyr} G$ mutant never germinates or

Table 5 Optimization of AMT conditions in $100 \mathrm{ml}$ of liquid IM

\begin{tabular}{|c|c|c|c|c|c|c|c|}
\hline \multirow[t]{2}{*}{$\begin{array}{l}\text { Number of } \\
\text { conidia }\end{array}$} & \multirow{2}{*}{$\begin{array}{l}\text { Number of } \\
\text { Agrobacterium } \\
\text { cells }\end{array}$} & \multirow[t]{2}{*}{$\begin{array}{l}\text { Ratio of conidia: } \\
\text { Agrobacterium }\end{array}$} & \multicolumn{5}{|c|}{$\begin{array}{l}\text { Mean of transformants } \pm S D / 10^{7} \\
\text { conidia/100 } \mathrm{ml} \mathrm{IM}\left(\mathrm{n}^{\mathrm{a}} \geq 3\right)\end{array}$} \\
\hline & & & $24 \mathrm{~h}$ & $36 \mathrm{~h}$ & $48 \mathrm{~h}$ & $60 \mathrm{~h}$ & $72 \mathrm{~h}$ \\
\hline $1 \times 10^{7}$ & $5 \times 10^{6}$ & $1: 0.5$ & $1 \pm 4$ & $16 \pm 15$ & $40 \pm 27$ & $41 \pm 23$ & $25 \pm 16$ \\
\hline $1 \times 10^{7}$ & $5 \times 10^{7}$ & $1: 5$ & $16 \pm 27$ & $60 \pm 29$ & $92 \pm 88$ & $55 \pm 16$ & $41 \pm 26$ \\
\hline $1 \times 10^{7}$ & $5 \times 10^{8}$ & 1: 50 & $23 \pm 20$ & $132 \pm 82$ & $217 \pm 141$ & $292 \pm 211$ & $148 \pm 101$ \\
\hline $1 \times 10^{7}$ & $5 \times 10^{9}$ & 1: 500 & $5 \pm 8$ & $3 \pm 5$ & $11 \pm 12$ & $10 \pm 8$ & $11 \pm 14$ \\
\hline
\end{tabular}

\footnotetext{
${ }^{a} n$, number of independent experiments.
} 
Table 6 Optimization of transformation conditions for A. aculeatus pyrG mutant

\begin{tabular}{|c|c|c|c|c|c|c|c|}
\hline \multirow[t]{2}{*}{ Strain } & \multirow[t]{2}{*}{$\begin{array}{l}\text { Germination } \\
\text { time (h) }\end{array}$} & \multirow[t]{2}{*}{$\begin{array}{l}\text { Uridine } \\
\text { Concentration in IM }\end{array}$} & \multicolumn{5}{|c|}{$\begin{array}{l}\text { Co-cultivation time and Mean of transformants } \pm \text { SD } \\
/ 10^{7} \text { conidia/100 ml IM }\end{array}$} \\
\hline & & & $24 \mathrm{~h}$ & $36 \mathrm{~h}$ & $48 \mathrm{~h}$ & $60 \mathrm{~h}$ & $72 \mathrm{~h}$ \\
\hline \multirow[t]{3}{*}{ WT } & 0 & - & $23 \pm 20$ & $132 \pm 82$ & $217 \pm 141$ & $292 \pm 211$ & $148 \pm 101$ \\
\hline & 0 & $0.01 \%$ & $81 \pm 72$ & $73 \pm 36$ & $116 \pm 52$ & $147 \pm 64$ & $82 \pm 45$ \\
\hline & 0 & $0.2 \%$ & $10 \pm 12$ & $193 \pm 98$ & $174 \pm 106$ & $187 \pm 130$ & $131 \pm 118$ \\
\hline \multirow[t]{4}{*}{ pyrG } & 0 & $0.01 \%$ & 0 & $50 \pm 38$ & $24 \pm 33$ & $15 \pm 12^{a}$ & $16 \pm 13$ \\
\hline & 0 & $0.2 \%$ & 0 & $66 \pm 71$ & $58 \pm 95$ & $135 \pm 155^{a}$ & $33 \pm 54$ \\
\hline & 24 & $0.01 \%$ & $91 \pm 66$ & $122 \pm 62$ & $50 \pm 49$ & $140 \pm 82^{\mathrm{a}}$ & $50 \pm 60$ \\
\hline & 24 & $0.2 \%$ & $38 \pm 24$ & $26 \pm 10$ & $23 \pm 11$ & $2 \pm 5^{a}$ & $12 \pm 18$ \\
\hline
\end{tabular}

WT, the $A$. aculeatus wild-type strain; $n=3$ except for a $(n=2)$

forms transformants in AMT without the addition of uridine to liquid IM (data not shown). Taking these data into account, we presumed that the germination of conidia and the physiological conditions of the recipient cells were critical for T-DNA uptake in A. aculeatus. Thus, we next investigated the AMT conditions using germinated conidia from the pyrG mutant that were pregrown for $24 \mathrm{~h}$. Co-cultivation for $36 \mathrm{~h}$ with $0.01 \%$ uridine produced 122 transformants per $10^{7}$ conidia per $100 \mathrm{ml}$ of IM on average, which was 2 - to 5 -fold more than the amount obtained by the AMT method optimized for the wild-type strain; i.e. 48-hours co-cultivation with $0.01 \%$ uridine ( $24 \pm 33$ transformants) or $0.2 \%$ uridine added (58 \pm 95 transformants). Our data demonstrate that the optimization of AMT for each isolate is necessary to establish efficient AMT methods.

\section{Mitotic stability of the integrated T-DNA}

The fates of the T-DNA in the genomes of the transformants were assessed by Southern blot analyses using genomic DNA isolated from 120 randomly selected transformants and a DNA probe that hybridizes to the $h p h$ gene. These results revealed that the T-DNA integrated into the genomes of all transformants at random because DNA bands of various sizes were hybridized. The mitotic stability of the integrated DNA in 9 randomly selected transformants was examined after 5 rounds of mitosis on MM without hygromycin B, followed by culture on MM including hygromycin B. The average and standard deviation of the ratio of the number of colonies formed on MM with hygromycin B to that on MM without hygromycin B was $1.1 \pm 0.13$. The colony morphology also remained unchanged during culture. These data indicate that the integrated T-DNA is stably maintained in the recipient genome.

\section{Integration mode of the T-DNA into A. aculeatus genomic DNA}

The effect of the co-cultivation conditions on the TDNA integration pattern was investigated by Southern blot analyses. The recipient genomic DNA was isolated from transformants obtained under the following co-cultivation conditions: the ratio of bacterial cells to target conidia was $5 \times 10^{3}$ or $1 \times 10^{4}$ on solid IM (Table 3,48 h) and 50 in liquid IM (Table 5, 48 h). Twenty, sixty, and forty transformants obtained under each set of conditions were randomly selected and analyzed. The overall frequencies of the single-locus integration of the TDNA were 95\%, 90\%, and 90\%, respectively (Table 7). Integration events predominantly occurred at a single locus under all the tested conditions, whereas further itemization of the integration pattern revealed differences. When the co-cultivation was performed on solid IM for $48 \mathrm{~h}$ at the ratio of $A$. tumefaciens to target conidia of $5 \times 10^{3}$, and which yielded 7 transformants per 1 $\times 10^{4}$ conidia (Table 3 ), on average, the T-DNA predominantly integrated into the recipient genome as a single copy (50\%). Increasing the ratio of $A$. tumefaciens to

Table 7 T-DNA integration patterns observed in transformants obtained under the indicated cocultivation conditions

\begin{tabular}{llll}
\hline Integration pattern & \multicolumn{3}{l}{ Number of transformants } \\
\cline { 2 - 4 } & $\begin{array}{l}1: 5000 \\
\text { on plate }\end{array}$ & $\begin{array}{l}1: 10^{4} \text { on } \\
\text { plate }^{\mathrm{a}}\end{array}$ & $\begin{array}{l}1: 50 \text { in } \\
\text { liquid }^{\mathrm{a}}\end{array}$ \\
\hline 1 copy & 10 & 18 & 16 \\
& $(50.0 \%)$ & $(30.0 \%)$ & $(40.0 \%)$ \\
1 copy & 3 & 14 & 5 \\
+ vector backbone & $(15.0 \%)$ & $(23.3 \%)$ & $(12.5 \%)$ \\
\hline multiple copies at & 5 & 3 & 8 \\
single locus & $(25.0 \%)$ & $(5.0 \%)$ & $(20.0 \%)$ \\
multiple copies at & 1 & 19 & 7 \\
single locus + vector & $(5.0 \%)$ & $(31.7 \%)$ & $(17.5 \%)$ \\
backbone & & & 1 \\
\hline multiple copies at & 1 & 1 & $(2.5 \%)$ \\
different loci & $(5.0 \%)$ & $(1.7 \%)$ & 3 \\
multiple copies at & 0 & 5 & $(7.5 \%)$ \\
different loci + vector backbone & $(0 \%)$ & $(8.3 \%)$ & 40 \\
\hline Number of & 20 & 60 & $(100 \%)$ \\
transformants analyzed & $(100 \%)$ & $(100 \%)$ & \\
\hline
\end{tabular}

a, the ratio of $A$. aculeatus conidia to $A$. tumefaciens cells. 
target conidia to $1 \times 10^{4}$ improved the transformation frequency to 30 transformants per $1 \times 10^{4}$ conidia (Table 3, $48 \mathrm{~h}$ ) on average; the single-copy integration of the T-DNA decreased to $30 \%$, but the frequency of T-DNA integration into a single locus with the vector backbone typically increased to $55 \%$. When the co-cultivation was performed in liquid IM at the ratio of $A$. tumefaciens to target conidia of 50, the yield was 217 transformants per $1 \times 10^{7}$ conidia, and single-copy integration of the T-DNA was predominant (40\%). The TDNA integration with the vector backbone was also relatively low. The AMT method optimized for liquid IM resulted in more transformants harboring the $\mathrm{T}$ DNA integrated into a single locus without the vector backbone. Thus, we concluded that co-cultivation in liquid IM was suitable for the AMT of $A$. aculeatus.

\section{Recovery of flanking sequences}

To obtain the DNA sequences flanking the T-DNA inserts in the recipient genome, we adopted TAIL-PCR and inverse PCR using genomic DNA isolated from randomly selected transformants. We first performed TAIL-PCR, which produced readable segments of the recipient genome adjacent to both sides of the T-DNA from all transformants (13/13 transformants) harboring the T-DNA as a single copy. However, when the TDNA existed in the recipient genome with the vector backbone or as concatemeric bands with or without the vector backbone at a single locus, segments derived from the vector or the T-DNA tended to be amplified rather than the recipient genome. Therefore, the DNA sequences flanking the T-DNA inserts could only be identified on one side in 5 of 13 transformants. The TDNA integration with a vector backbone made it difficult to rescue the flanks of the T-DNA border. To rescue the recipient genome flanking the T-DNA irrespective of its integration mode, we performed inverse PCR or TAIL-PCR on the recipient genome digested with restriction enzymes, as described in the Materials and Methods section. We considered that the trimming of a vector backbone or concatemeric T-DNA fragments attached to the recipient genomic DNA would increase the rescue rate for either side flanking the T-DNA. Indeed, the flanks were obtained in 5 out of 6 transformants by TAIL-PCR and 5 out of 5 transformants by inverse PCR using recipient genomic DNA digested with restriction enzymes. However, it remains challenging to rescue the flanks if the vector backbone is attached to both sides of the T-DNA or if the selected restriction sites do not exist near the T-DNA integration locus. In this case, we confirmed that the far side of the recipient genome was effectively rescued by TAIL-PCR using circular DNA produced by digestion with a restriction enzyme followed by ligation. Furthermore, we were able to identify T-DNA flanking sequences even though the T-DNA fragments were integrated into different loci, although only in one transformant. Our data indicate that the tagged genes in almost all of the transformants could be recovered by a combination of TAILPCR and inverse PCR, which satisfies the requirement for a successful gene tagging protocol.

Based on the above sequence analyses, we investigated how the T-DNA was inserted into the recipient genome without a large deletion of the T-DNA bordering sequence or the recipient genome sequence. Except in cases where the recipient genome was obtained with a short vector sequence, truncation of the T-DNA termini occurred in $89.5 \%(17 / 19)$ and $15.8 \%(3 / 19)$ of the border sequences on the left and right borders, respectively. Although truncations occurred with high frequency at the left terminus, the length of the truncation at the left T-DNA terminus was $8 \mathrm{bp}$ on average and $42 \mathrm{bp}$ at the longest. As shown in Figure $1 \mathrm{~A}$ and $\mathrm{B}$, the fungal DNA at the integration site had obvious microcomplimentarities with the left terminus of the T-DNA but not with the right terminus. This requirement of short stretches

\section{A}

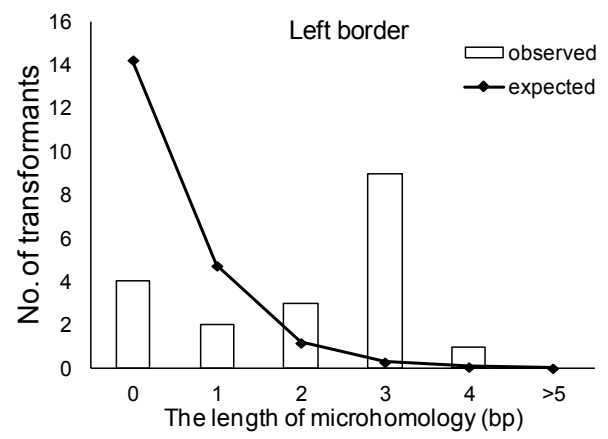

B

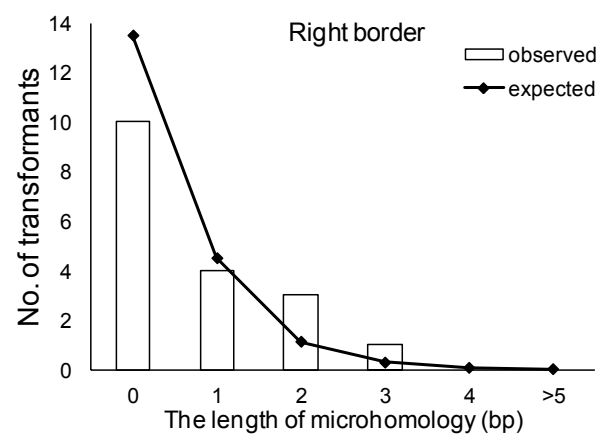

Figure 1 Distribution of the regions with microhomology between the host genome and the left-border (A) and rightborder (B) sequences. The open bars show the distributions of TDNA possessing each microhomologous region, and the solid lines show the expected length of microhomology. 


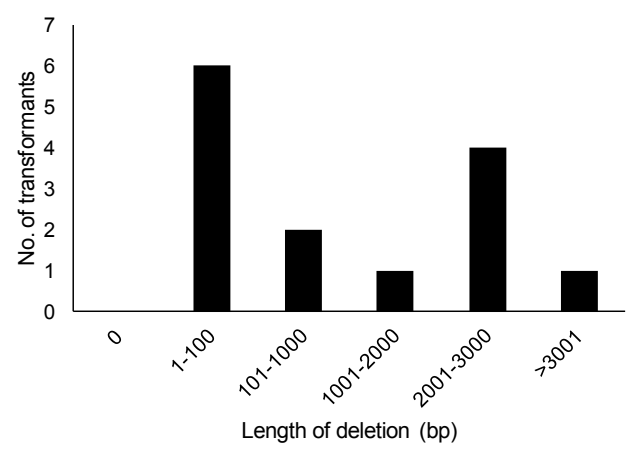

Figure 2 A frequency distribution for different size classes of recipient genome deletions among 13 T-DNA integration sites for which the sequences of both junctions were determined.

of homology at crossover points may have led to deletions at the left terminal integration sites.

A comparison of both sides of the flanking sequence tags adjacent to the T-DNA with the draft genome sequence of $A$. aculeatus revealed that deletion of the recipient genome occurred in all 14 transformants analyzed, and the average length of the deletions was 1,393 bp. As shown in Figure 2, the predominance of deletions, 6 out of 14 (42.9\%), was shorter than $100 \mathrm{bp}$. Deletions longer than 2,001 bp, including the longest deletion of $6,913 \mathrm{bp}$, occurred in 5 transformants (35.7\%). Such deletions are acceptable for functional genomic analyses in $A$. aculeatus.

\section{Isolation and characterization of albino mutants}

During the process of establishing our AMT protocols, 2 albino mutants, $A$. aculeatus alb1 and alb2, which formed colorless conidia, emerged on selective media from among approximately 11,000 transformants. Using these mutants, we assessed whether or not the established AMT method was applicable for random insertional mutagenesis. We first indentified genes disrupted by the T-DNA insertion in the alb1 mutant. A Southern blot analysis revealed that the T-DNA was inserted into a single locus in the alb1 mutant, so we performed TAIL-PCR to identify the T-DNA flanking sequences. A sequence analysis of the amplified flanks revealed that the T-DNA was inserted at $70 \mathrm{bp}$ upstream of the polyketide synthase gene (the $p k s P$ gene $($ AapksP), Accession No. AB576490) and caused a 1,002-bp deletion in the recipient genome, which resulted in the deletion of a putative TATA box on the $p k s P$ promoter. AapksP was the only predicted gene near the T-DNA integration locus; it had $69.5 \%$ identity to the $w A$ gene of $A$. nidulans (Accession no. Q03149) and 68.7\% identity to the pksP gene of A. fumigatus (Accession no. EDP55264), which are involved in melanin biosynthesis and conidial pigmentation. To confirm that the deletion of the
Aapksp locus resulted in the formation of the albino mutant, complementation tests were performed (Figure 3A). Transformation of the alb1 mutant with pAURPksP yielded transformants with black conidia, whereas all transformants of alb1 with pAUR325 remained albino (Figure 3B). Furthermore, the albino phenotype of the alb2 mutant was also complemented by transformation with pAUR-PksP (data not shown). Therefore, the mutation point resulting in the albino mutant corresponded to the locus for which the sequence was obtained as the T-DNA flank, thus demonstrating that AMT is a useful toolkit for gene tagging.

\section{Discussion}

The results presented here demonstrate that the developed AMT method is applicable for high-throughput insertional mutagenesis in A. aculeatus. This method was developed by optimizing parameters that affect the AMT frequencies such as AS concentration, the ratio of A. tumefaciens cells to A. aculeatus cells, co-cultivation conditions, and starting materials (Michielse et al. 2008). Using the AMT method optimized for A. aculeatus wild-type, 30 transformants per $10^{4}$ conidia were formed, on average, when using solid IM for co-cultivation. The transformation frequency on solid IM was relatively higher than that for other fungi, e.g., 150-300 transformants per $10^{6}$ recipients in C. lagenarium, 200 transformants per $10^{6}$ recipients in A. awamori, 5 transformants per $10^{7}$ recipients in $A$. niger, and 50 transformants per $10^{5}$ recipients in $N$. crassa (de Groot et al. 1998,; Tsuji et al. 2003). A. tumefaciens C58C1 and a binary vector, pBIG2RHPH2, seem to be appropriate for the AMT of $A$. aculeatus because the transformation frequency is influenced by differences in the binary vector or bacterial strain used (Mullins et al. 2001).

Another aspect that must be considered to establish efficient AMT is the integration mode of the T-DNA into the recipient genome. In F. oxysporum, A. awamori, and $C$. lagenarium, single-copy integration events are predominantly observed (de Groot et al. 1998,; Mullins et al. 2001,; Tsuji et al. 2003). However, the fate of the T-DNA in A. aculeatus depends on the AMT method. A high density of $A$. tumefaciens increased the transformation frequency; however, undesirable integrations of the T-DNA such as multiple-copy integrations at a single locus, with or without the vector backbone, or integration at multiple loci also increased in A. aculeatus, as previously reported in Blastomyces dermatitidis (Sullivan et al. 2002) and in Suillus bovinus (Hanif et al. 2002). In contrast, a low density of $A$. tumefaciens yielded fewer transformants; however, the T-DNA predominantly existed as a single copy in the recipient genome. Although we expected to obtain more transformants by co-cultivating A. tumefaciens cells and fungal conidia in 

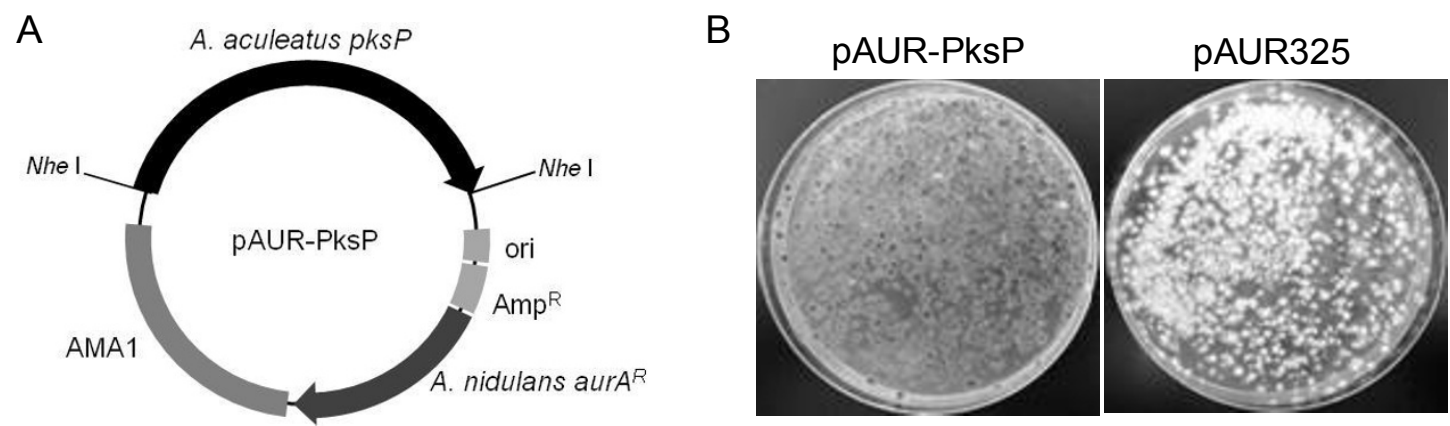

Figure 3 Complementation of albino mutants. (A) Diagram of the transformation vector for the A. aculeatus alb1 and alb2 mutants. (B) Pigmented colonies formed in transformants of alb1 with pAUR-pksP (left), but transformants with pAUR325 remained albino (right).

high quantities on solid or liquid IM, this technique did not yield more transformants. There is a limit to the concentration of bacterial cells and fungal conidia for efficient AMT that is likely related to the physiological conditions of $A$. tumefaciens and the recipient fungal cells (Meyer et al. 2003). The best AMT method should increase the number of transformants harboring the $\mathrm{T}$ DNA as a single copy, which is a criterion with apparently opposing contributing factors. Thus, we hereby propose that AMT using liquid IM satisfies this criterion for random insertional mutagenesis.

The transformation frequency for the A. aculeatus uridine auxotroph tended to be lower than that of the wild type with the same AMT method (Table 6). When acetamide utilization, uridine prototrophy, phleomycin resistance, or hygromycin resistance was used to select transformants in A. awamori, average transformation frequencies of $0.2,40,80$, and 200 transformants per $10^{6}$ conidiospores were obtained (Michielse et al. 2008,). The transformation frequency apparently varies depending on the genetic background of the recipient and the transformation conditions (Covert et al. 2001,; de Groot et al. 1998; Fitzgerald et al. 2003,; Michielse et al. 2004,; Sullivan et al. 2002). However, the transformation frequency among different isolates has been assessed by using the same AMT method. Our data show an improvement of transformation frequency by optimizing AMT conditions according to the recipient cells, and which supports that AMT means can be applicable to transform variety types of the recipient cells.

During the optimization of AMT conditions, 2 albino mutants, the Aapksp disruptants, were discovered among 11,000 transformants. To isolate one albino mutant with a $95 \%$ probability out of 5,500 transformants from the approximately $35-\mathrm{Mb}$ genome of $A$. aculeatus, it was calculated that the T-DNA must disrupt gene the function in a 19-kb region around the TDNA integration locus (Krysan et al. 1999). The 1,002bp deletion at the AapksP locus in the alb1 mutant was relatively larger than those reported for $M$. oryzae and Arabidopsis, in which the majority of deletions ranged from 1 to $35 \mathrm{bp}$ and 11 to $100 \mathrm{bp}$, respectively (Brunaud et al 2002,; Choi et al. 2007,; Forsbach et al. 2003). Furthermore, the coding region of AapksP is relatively large at 6,645 bp; however, it is not large enough to increase the probability of isolating two albino mutants from 11,000 transformants. Although the T-DNA integration was initially thought to be random in Arabidopsis (Azpiroz-Leehan and Feldmann, 1997,) and yeast (Bundock et al. 2002), the randomness of the integration has been controversial given the accumulated data indicating the nonrandom nature of T-DNA insertion. In Arabidopsis, the T-DNA integration occurs between the recipient genome and microhomologous sequences of the T-DNA composed of 5-bp and 2-bp sequences on the left border and right border, respectively (Brunaud et al. 2002,). Furthermore, obvious biases were reported for insertions in the 5'- and 3'-regulatory regions outside the coding regions for 500-bp regions and in introns rather than in exons in the rice genome (Chen et al. 2003), outside of the transcribed regions in Arabidopsis (Sessions et al. 2002), and in the intergenic region in $M$. oryzae (Choi et al. 2007). In A. aculeatus, microhomology was observed on the left border of the T-DNA; however, the other bias has not been identified thus far, although we are in the process of analyzing more transformants. A combination of T-DNA bias integration and a certain deletion length in the recipient genome can contribute to the facilitation of high-throughput insertional mutagenesis by AMT. We expect that the AMT method established here will contribute to functional genetic analyses in A. aculeatus. Moreover, we expect that the techniques described here can be applied to establish AMT techniques for other organisms.

\section{Acknowledgements}

We are grateful to Dr. Tsuji (Kyoto Prefecture University) and Dr. Kato (Meijo University) for their helpful discussions, and for providing the pBIG2RHPH2 
plasmid and Agrobacterium tumefaciens C58C1. This research was supported by a Grant-in-Aid for Young Scientists (B) (\#20780058) from The Ministry of Education, Culture, Sports, Science, and Technology in Japan (MEXT).

\section{Competing interests}

The authors declare that they have no competing interests.

Received: 29 November 2011 Accepted: 14 December 2011 Published: 14 December 2011

\section{References}

Adachi H, Tani S, Kanamasa S, Sumitani J, Kawaguchi T (2009) Development of a homologous transformation system for Aspergillus aculeatus based on the $\mathrm{SC}$ gene encoding ATP-sulfurylase. Biosci Biotech Bioch 73:1197-1199. doi:10.1271/bbb.80772.

Azpiroz-Leehan R, Feldmann KA (1997) T-DNA insertion mutagenesis in Arabidopsis: going back and forth. Trends Genet 13:152-156. doi:10.1016/ S0168-9525(97)01094-9.

Bachert B, Meyer TF (2006) Type IV secretion systems and their effectors in bacterial pathogenesis. Curr Opin Microbiol 9:207-217. doi:10.1016/j. mib.2006.02.008.

Betts MF, Tucher SL, Galadima N, Meng Y, Patel G, Li L, Donofrio N, Floyd A, Nolin S, Brown D, Mandel MA, Mitchell TK, Xu JR, Dean RA, Farman ML, Orbach MJ (2007) Development of a high throughput transformation system for insertional mutagenesis in Magnaporthe oryzae. Fungal Genet Biol 44:1035-1049. doi:10.1016/j.fgb.2007.05.001.

Braumann I, van den Berg M, Kempken F (2007) Transposons in biotechnologically relevant strains of Aspergillus niger and Penicillium chrysogenum. Fungal Genet Biol 44:1399-1414. doi:10.1016/.jfgb.2007.07.010.

Brown JS, Aufauvre-Brown A, Holden DW (1998) Insertional mutagenesis of Aspergillus fumigatus. Mol Gen Genet 259:327-335. doi:10.1007/ s004380050819.

Brunaud W, Balzergue S, Dubreucq B, Aubourg S, Samson F, Chauvin S, Bechtold N, Cruaud C, DeRose R, Pelletier G, Lepiniec L, Caboche M, Lecharny A (2002) T-DNA integration into the Arabidopsis genome depends on sequences of pre-insertion sites. EMBO Rep 3:1152-1157. doi:10.1093/ embo-reports/kvf237.

Bundock P, van Attikum H, den Dulk-Ras A, Hooykaas PJJ (2002) Insertional mutagenesis in yeasts using T-DNA from Agrobacterium tumefaciens. Yeast 19:529-536. doi:10.1002/yea.858.

Chen S, Jin W, Wang M, Zhang F, Zhou J, Jia Q, Wu Y, Liu F, Wu P (2003) Distribution and characterization of over 1000 T-DNA tags in rice genome. Plant J 36:105-113. doi:10.1046/j.1365-313X.2003.01860.x.

Choi J, Park J, Jeon J, Chi MH, Goh J, Yoo SY, Park J, Jung K, Kim H, Park SY, Rho HS, Kim S, Kim BR, Han SS, Kang S, Lee YH (2007) Genome-wide analysis of T-DNA integration into the chromosomes of Magnaporthe oryzae. Mol Microbiol 66:371-382. doi:10.1111/j.1365-2958.2007.05918.x.

Christie PJ (2001) Type IV secretion: intercellular transfer of macromolecules by systems ancestrally related to conjugation machines. Mol Microbiol 40:294-305. doi:10.1046/j.1365-2958.2001.02302.x.

Covert SF, Kapoor P, Lee M, Briley A, Nairn CJ (2001) Agrobacterium-mediated transformation of Fusarium circinatum. Mycol Res 105:259-264. doi:10.1017/ S0953756201003872.

Daboussi MJ (1996) Fungal transposable elements: generators of diversity and genetic tools. J Genet 75:325-339. doi:10.1007/BF02966312.

de Groot MJA, Bundock P, Hooykaas PJJ, Beijersbergen AGM (1998) Agrobacterium tumefaciens-mediated transformation of filamentous fungi. Nat Biotechnol 16:839-842. doi:10.1038/nbt0998-839.

Feldmann KA (1991) T-DNA insertion mutagenesis in Arabidopsis: mutational spectrum. Plant J 1:71-82. doi:10.1111/j.1365-313X.1991.00071.x.

Fitzgerald AM, Mudge AM, Gleave AP, Plummer KM (2003) Agrobacterium and PEG-mediated transformation of the phytopathogen Venturia inaequalis. Mycol Res 107:803-810. doi:10.1017/S0953756203008086.

Forsbach A, Schubert D, Lechtenberg B, Gils M, Schmidt R (2003) A comprehensive characterization of single-copy T-DNA insertions in the Arabidopsis thaliana genome. Plant Mol Biol 52:161-176. doi:10.1023/ A:1023929630687.

Hanif M, Pardo AG, Gorfer M, Raudaskoski M (2002) T-DNA transfer and integration in the ectomycorrhizal fungus Suillus bovinus using hygromycin B as a selectable marker. Curr Genet 41:183-188. doi:10.1007/s00294-002-0297-8.
Idnurm A, Reedy JL, Nussbaum JC, Heitman F (2004) Cryptococcus neoformans virulence gene discovery through insertional mutagenesis. Eukaryot Cell 3:420-429. doi:10.1128/EC.3.2.420-429.2004.

Kanamasa S, Kawaguchi T, Takada G, Kajiwara S, Sumitani J, Arai M (2007) Development of an efficient production for beta-mannosidase by the creation of an overexpression system in Aspergillus aculeatus. Lett Appl Microbiol 45:142-147. doi:10.1111/j.1472-765X.2007.02160.x.

Koncz C, Nemeth K, Redei GP, Schell J (1992) T-DNA insertional mutagenesis in Arabidopsis. Plant Mol Biol 20:963-976. doi:10.1007/BF00027166.

Krysan PJ, Young JC, Sussman MR (1999) T-DNA as an insertional mutagen in Arabidopsis. Plant Cell 11:2283-2290

Linnemannstöns P, Vob T, Hedden P, Gaskin P, Tudzynski B (1999) Deletions in the Gibberellin biosynthesis gene cluster of Gibberella fujikuroi by restriction enzyme-mediated mutagenesis. Appl Environ Microbiol 65:2558-2564

Liu YG, Mitsukawa N, Oosumi T, Whittier RF (1995) Efficient isolation and mapping of Arabidopsis thaliana T-DNA insert junctions by thermal asymmetric interlaced PCR. The Plant J 8:457-463. doi:10.1046/j.1365313X.1995.08030457.X.

Meng Y, Patel G, Heist M, Betts MF, Tucher SL, Galadima N, Donofrio NM, Brown D, Mitchell TK, Li L, XU JR, Orbach M, Thon M, Dean RA, Farman ML (2007) A systematic analysis of T-DNA insertion events in Magnaporthe oryzae. Fungal Genet Biol 44:1050-1064. doi:10.1016/j.fgb.2007.04.002.

Meyer V, Mueller D, Strowig T, Stahl U (2003) Comparison of different transformation methods for Aspergillus giganteus. Curr Genet 43:371-377. doi:10.1007/s00294-003-0406-3.

Michielse CB, Ran AFJ, van den Hondel CAMJJ (2004) The Aspergillus nidulans amdS gene as a marker for the identification of multicopy T-DNA integration events in Agrobacterium-mediated transformation of Aspergillus awamori. Curr Genet 45:399-403. doi:10.1007/s00294-004-0500-1.

Michielse CB, Arentshorst M, Ran AFJ, van den Hondel CAMJJ (2005) Agrobacterium-mediated transformation leads to improved gene replacement efficiency in Aspergillus awamori. Fungal Genet Biol 42:9-19. doi:10.1016/j. fgb.2004.06.009.

Michielse CB, Hookaas PJJ, van den Hondel CAMJJ, Ran AFJ (2005) Agrobacteirum-mediated transformation as a tool for functional genomics in fungi. Curr Genet 48:1-17. doi:10.1007/s00294-005-0578-0.

Michielse CB, Hooykaas PJJ, van den Hondel CAMJJ, Ran AFJ (2008) Agrobacterium-mediated transformation of the filamentous fungus Aspergillus awamori. Nat Protoc 3:1671-1678. doi:10.1038/nprot.2008.154.

Mullins ED, Chen X, Romaine P, Raina R, Geiser DM, Kang S (2001) Agrobacterium-mediated transformation of Fusarium oxysporum: an efficient tool for insertional mutagenesis and gene transfer. Phytopathology 91:173-180. doi:10.1094/PHYTO.2001.91.2.173.

Murao S, Kanamoto J, Arai M (1979) Isolation and identification of a cellulolytic enzyme producing microorganism. J Ferment Technol 57:151-156

Nyilasi I, Papp T, Csernetics A, Vágvölgyi C (2008) Agrobacterium tumefaciensmediated transformation of the zygomycete fungus Backusella lamprospora. J Basic Microb 48:59-64. doi:10.1002/jobm.200700221.

Ooi T, Morotomi K, Kinoshita S, Honda J, Ueda S, Arai M (1999) Analysis of 5'upstream non-coding region of $\mathrm{Fl}$-carboxymethyl cellulase gene from Aspergillus aculeatus. Biotech Letters 21:735-739. doi:10.1023/ A:1005534925774.

Roberts RL, Metz M, Monks DE, Mullaney ML, Hall T, Nester EW (2003) Purine synthesis and increased Agrobacterium tumefacience transformation of yeast and plants. Proc Natl Acad Sci USA 100:6634-6639. doi:10.1073/ pnas. 1132022100 .

Sessions A, Burke E, Presting G, Aux G, McElver J, Patton D, Dietrich B, Ho T, Bacwaden J, Ko C, Clarke JD, Cotton D, Bullis D, Snell J, Miguel T, Hutchison D, Kimmerly B, Mitzel T, Katagiri F, Glazebrook J, Law M, Goff SA (2002) A high-throughput Arabidopsis reverse genetics system. Plant Cell 14:2985-2994. doi:10.1105/tpc.004630.

Sugui JA, Chang YC, Kwon-Chung KJ (2005) Agrobacterium tumefaciens-mediated transformation of Aspergillus fumigatus: an efficient tool for insertional mutagenesis and target gene disruption. Appl Environ Microbiol 71:1798-1802. doi:10.1128/AEM.71.4.1798-1802.2005.

Sullivan TD, Rooney RJ, Klein BS (2002) Agrobacterium tumefaciens integrates transfer DNA into single chromosomal sites of dimorphic fungi and yields homokaryotic progeny from multinucleate yeast. Eukaryot Cell 1:895-905. doi:10.1128/EC.1.6.895-905.2002. 
Takada G, Kawaguchi T, Sumitani J, Arai M (1998) Cloning, nucleotide sequence, and transcriptional analysis of Aspergillus aculeatus no. F-50 cellobiohydrolase I (cbhl) gene. J Ferment Bioeng 85:1-9

Takada G, Kawasaki M, Kitawaki M, Kawaguchi T, Sumitani J, Izumori K, Arai M (2002) Cloning and transcription analysis of the Aspergillus aculeatus No. F-50 endoglucanase, 2 ( $\mathrm{cmc}$ ) gene. J Biosci Bioeng 94:482-485

Tsuji G, Fujii S, Fujihara N, Hirose C, Tsuge S, Shiraishi T, Kubo Y (2003) Agrobacterium tumefaciens-mediated transformation for random insertional mutagenesis in Colletotrichum lagenarium. J Gen Plant Pathol 69:230-239. doi:10.1007/s10327-003-0040-4.

doi:10.1186/2191-0855-1-46

Cite this article as: Kunitake et al: Agrobacterium tumefaciens-mediated transformation of Aspergillus aculeatus for insertional mutagenesis. $A M B$ Express 2011 1:46.

\section{Submit your manuscript to a SpringerOpen ${ }^{\circ}$ journal and benefit from:}

- Convenient online submission

- Rigorous peer review

- Immediate publication on acceptance

- Open access: articles freely available online

- High visibility within the field

- Retaining the copyright to your article

Submit your next manuscript at $\gg$ springeropen.com 